\title{
Commanding Right and Forbidding Wrong in Islamic Thought
}

\author{
Michael Cook \\ Cambridge, UK: Cambridge University \\ Press, 2000. 702 pages.
}

This book, an historical survey of the Islamic injunction to command right and forbid wrong, a biographical exposé of Muslims who understood and practiced this principle, and a bibliographical reference, is a welcome and timely addition to the literature on Islamic thought. Detailed and extensive, yet not particularly difficult to read, it is equally accessible to all readers. Its main theme is the basic Islamic individual and communal duty to stop other people from doing wrong. Cook contends that few cultures have paid such meticulous concern to this matter, despite the issue's intelligibility in just about any culture.

As a central Islamic tenet, this principle could not be ignored, and yet its sociopolitical implications and consequences made it the focus of rigorous attention by Muslim scholars. The doctrine inexorably brings up the balancing and equally sacrosanct value of privacy, together with issues of knowledge, specialization, competence, and stability - the "how" of the whole matter. After all, the act of forbidding wrong was not supposed to undermine the principle by becoming an intrusive breach of privacy, an excursus into social prying, or a potential justification for unmitigated rebellion against the state.

The book consists of five parts comprising 20 chapters. Part I sets the descriptive framework by elaborating the normative material found in the Qur'an, Qur'anic exegesis, tradition, and biographical literature about early Muslims. Part II is dedicated to the Hanbali school ince its foundation by Ahmad ibn Hanbal (d. 241/855) in Baghdad. The author traces its shifting influences in Damascus and Najd, where the school continues to have a hold in the Saudi state to this day. Part III deals with the Mu'tazilis and their Zaydi and Imami heirs, all of which, Cook contends, provide the richest documentation for the intellectual history of forbidding wrong. The remaining Sunni schools of thought, the Khariji Ibadis, together with a chapter on al-Ghazali's tackling of the duty and another chapter pulling together the discussion of classical Islam, comprise Part IV. Finally, Part V surveys the duty's salience in modern Islamic thought and developments in both the Sunni and Imami schools and engages in a comparative exercise with this duty's pre-Islamic antecedents and with non-Islamic cultures, including the modern West. 
Cook points out that this duty's doctrinal justification is based upon Qur'an 3:104, other verses, and Prophetic tradition. In the latter case, the most significant is the "three modes" tradition calling upon Muslims to right a wrong with the hand, the tongue, or, at a minimum, the heart. Conjoined is another tradition on speaking the truth to an unjust ruler or tyrant, even at the peril of death, as the highest manifestation of jihad. However, these positively activist verses and traditions are countered by others of a more constraining and "downplaying" tendency, which perceives the duty to lapse in coming evil and wicked times (i.e., times of "utter corruption of values"). No agreed position about this time is clarified. However, Cook observes the significance of the "geographical provenance of the material." Activists derive disproportionately from Kufa (Iraq), the leading center of provincial opposition to Umayyad dominance (Syria). In contrast, most of the material downplaying the duty tends to come from Syria. This does not necessarily delve into the authenticity of the reporting or understanding, but perhaps underscores the conveyance of a distinct "political mood."

Adding to this complexity are the conditions under which the task is to be performed. Given the "three modes" of duty performance, who should adopt which mode of action or inaction, and how should one cope with the possible risks involved? Cook again points out that while the relevant Prophetic traditions were less vague and general than the Qur'anic references, they nevertheless did not elaborate much a precise code of conduct. After all, forbidding wrong belonged first to the "public space of Muslim society," including the state on one side and the individual's private domain on the other. While both harbored proclivities toward wrongdoing, one who performed this duty nevertheless had to contemplate the implications of power. The vast and intimidating concentration of might in the state contrasted with the more equitable balance vis-à-vis individual Muslims. Thus intrusion was more appealing than subversion. And it was the dialectics of these two tendencies that largely influenced competing scholarly opinions regarding the appropriate mode and code of conduct.

Were scholars to accommodate or confront the state? Some accommodating views, especially where violence was possible, espoused entrusting the ruler with forbidding wrong. However, confrontational opinions asserted that a wrongdoing state should be admonished. This often took the form of "rebuke" or "rebellion," each with its own constituency, a mainstream scholarly opinion endorsing the former and a minority opting for the latter.

In all cases, however, the duty had to be performed by one possessing "civility, knowledge, and probity" combined with a respect for privacy. 
These were necessary characteristics if the duty was to be performed correctly, with a clear sense of discernment as to which mode of action was more appropriate, and not to invite a worse wrongdoing than the one forbidden. For instance, such may be the case when one needs to reconcile forbidding wrong with a respect for privacy, the infringement upon which is itself wrong. As Cook observes, the duty is triggered when the wrong becomes public knowledge, for any wrong done in private is between the wrongdoer and God. Once private, they are best kept private. The implication is that these are matters best practiced by people with discernment (scholars), though not exclusively so, for forbidding wrong incorporates a radical value: "the principle that an executive power of the law of God is vested in each and every Muslim."

In the conclusion, Cook attempts to distinguish between Islamic and western notions of the duty by making the respective analytical distinction between "commanding good and forbidding wrong" and "rescue." The western principle is defined as the obligation to help victims or people in trouble regardless of whether the wrongdoing was intentional or not. The Islamic counterpart, however, aims to stop people from doing wrong irrespective of whether the wrongdoing has a human (or animal) victim or not. Each duty thus extends to an area that is foreign to the other, reflecting further on perceptions of privacy.

The western understanding considers certain kinds of behavior as private, irrespective of their domain of knowledge (substantive privacy), whereas in Islam moving from the private domain to public knowledge triggers different reactions, even if no one has been victimized (procedural privacy). If all wrongs must have victims, then what is left of the moral ground is reduced to a matter of rescue, largely at the expense of the notion of "sin." As the author points out, this "takes us back to a fundamental point of tension between the two world views: the standing, if any, of God in human affairs."

Many of those interested in Islamic thought will find this far-reaching book relevant and helpful. Unfortunately, Cook did not give sufficient attention to the tragic event at Karbala' and the martyrdom of Imam Hussain, both of which had an extraordinary impact on this doctrine's intellectual development. Whether directly mentioned in the scholastic works or not, it must have sunk into the Muslims' consciousness and had a determinate impact upon how they perceived the duty. After all, it is not difficult to see in Hussain the archetypal commander of good and forbidder of wrong, and an exemplar of the terrible price that sometimes must be paid while ful- 
filling this duty. As a matter of fact, Karbala' may have provided an overall contextual framework within which diverse and competing opinions about the duty were expressed. Very little is said about the extent to which it might have had a formative influence. An error of omission excused perhaps by the vastness of the topic and limitations of space.

Amr G. Sabet, Fellow Oxford Center for Islamic Studies Oxford, United Kingdom 